Bài báo khoa hoc

\title{
Đánh giá an ninh nước tỉnh Quảng Ngãi trong bối cảnh biến đổi khí hậu
}

Bùi Đức Hiếu ${ }^{*}$, Tạ Đình Thi², Huỹnh Thị Lan Hương ${ }^{3}$, Đặng Quang Thịnh ${ }^{3}$, Nguyễn Văn Đại ${ }^{3}$, Nguyễn Thị Liễu ${ }^{3}$, Nguyễn Anh Tuấn ${ }^{3}$

${ }^{1}$ Văn phòng Bộ Tài nguyên và Môi trường; duchieucect@gmail.com;

${ }^{2}$ Đại biểu Quốc hội Khóa XV, Tổng cục Biển và Hải đảo Việt Nam, Bộ Tài nguyên và Môi trường; tadinhthi@gmail.com;

${ }^{3}$ Viện Khoa học Khí tượng Thủy văn và Biến đổi khí hậu, Bộ Tài nguyên và Môi trường; huynhlanhuong@gmail.com; thinhdangq@gmail.com; nguyendai.tv@gmail.com; lieuminh2011@gmail.com; athnvn@gmail.com;

*Tác giả liên hệ: duchieucect@gmail.com, Tel.: +84-977365365

Ban Biên tập nhận bài: 8/7/2021; Ngày phản biện xong: 6/8/2021; Ngày đăng bài: 25/9/2021

Tóm tắt: Trên thế giới và ở Việt Nam, các nghiên cứu đề xuất đánh giá, lượng hóa mức độ an ninh nước đã được nghiên cứu nhưng chưa có nhiều nghiên cứu đánh giá an ninh nước trong bối cảnh biến đổi khí hậu, đặc biệt là việc áp dụng các bộ chỉ số/bộ tiêu chí để đánh giá. Nghiên cứu sử dụng phương pháp xây dựng bộ chỉ số để đánh giá an ninh nước trong bối cảnh biến đổi khí hậu ở tỉnh Quảng Ngãi. Nghiên cứu đã thu thập tài liệu, dữ liệu thực tiễn tại địa phương, kết quả điều tra khảo sát thực tế tại Quảng Ngãi. Thông qua phương pháp xin ý kiến chuyên gia, 17 chỉ số thành phần, 04 nhóm chỉ số chính được xác định để tính toán an ninh nước. Kết quả tính toán và so sánh cho thấy: (i) Chỉ số an ninh nước ở các thời kỳ tương lai đều thấp hơn so với thời kỳ hiện tại; (ii) Chỉ số an ninh nước ở tương lai có xét đến biến đổi khí hậu thấp hơn so với chỉ số không có biến đổi khí hậu; (iii) Chỉ số an ninh nước ở kịch bản RCP8.5 thấp hơn kịch bản RCP4.5 ở cùng thời kỳ 2046-2065. Kết quả của bài báo là tiền đề để đề xuất các giải pháp nhằm cải thiện an ninh nước ở tỉnh Quảng Ngãi.

Từ khóa: An ninh nước; Biến đổi khí hậu; Quảng Ngãi.

\section{Mở đầu}

Hiện nay, trên thế giới có nhiều khái niệm về an ninh nước; tại Việt Nam, hiện các cơ quan quản lý nhà nước, các đề tài nghiên cứu chủ yếu sử dụng cụm từ "an ninh nguồn nước" và "an ninh tài nguyên nước", nhưng về bản chất thì nội hàm là tương tự nhau. Tổng hợp lại thì định nghĩa của Ưy ban Liên hợp quốc về nước [1] bao hàm tương đối đầy đủ các nội dung về an ninh nước, cụ thể an ninh nước được đảm bảo khi một cộng đồng người dân được đáp ứng đủ nước một cách cơ bản cả về số lượng lẫn chất lượng để duy trì cuộc sống, phát triển kinh tế-xã hội, nhưng không bị ảnh hưởng bởi vấn đề ô nhiễm nước và các thảm hoạ liên quan đến nước; và quan trọng là tất cả các yếu tố nêu trên phải được duy trì trong điều kiện hệ sinh thái vẫn được bảo tồn, cuộc sống hoà bình, chính trị ổn định. Như vậy an ninh nước được đảm bảo khi: (i) Cộng đồng người dân có đủ nước để sử dụng cho đời sống, sinh hoạt, ăn uống và phục vự phát triển kinh tế-xã hội; (ii) Chất lượng nước được đảm bảo, sử dụng nước không bị ô nhiễm; (iii) Không bị ảnh hưởng bởi các thảm hoạ, thiên tai liên quan đến nước; (iv) Tất cả các yếu tố nêu trên phải được duy trì trong điều kiện hệ sinh thái vẫn được bảo tồn, 
cộng đồng sống trong hoà bình, chính trị ổn định. Nghiên cứu này sử dụng cụm từ "an ninh nước" với định nghĩa như trên.

Với khái niệm như vậy, việc đo lường an ninh nước không đơn giản và nhiều công cụ đã được thiết lập để lượng hóa đối tượng này [2]. Trong một đánh giá cho Khu vực Châu Ả-Thái Bình Dương [3], an ninh nước của 46 quốc gia có những điều kiện tài nguyên nước khác nhau và phát triển khác nhau được đánh giá thông qua 5 chỉ thị gồm: các nhu cầu căn bản, sản xuất lương thực, dòng chảy môi trường, quản lý rủi ro và sự độc lập. Đánh giá này là tương đối toàn diện, so sánh được nhiều các quốc gia với nhau nhưng phải đảm bảo có đủ số liệu, vì trên thực tế mỗi quốc gia có hệ cơ sử dữ liệu, cách thức tính toán, ngoại suy khác nhau. Trong nghiên cứu về chỉ số an ninh nước [4], để tính được an ninh nước cần 03 nhóm chỉ số phụ gồm tài nguyên nước, môi trường nước và kinh tế-xã hội, trong đó sử dụng 15 yếu tố được lựa chọn để thiết lập một đánh giá tổng hợp về an ninh nước ở lưu vực sông Hoàng Hà. Các chỉ tiêu cụ thể bao gồm: (i) Hợp phần tài nguyên nước; (ii) Hợp phần môi trường nước; (iii) Hợp phần kinh tế-xã hội.

Tại Việt Nam, các nghiên cứu liên quan đến an ninh nước vẫn chưa nhiều và chưa có nghiên cứu nào thiết lập được bộ chỉ số về an ninh nước cho khu vực nghiên cứu liên quan đển luận án. Đến nay có một số nghiên cứu liên quan đến an ninh nước gồm:

Năm 2015, Nghiên cứu "Phát triển và ứng dụng một khung đánh giá an ninh nguồn nước cho thành phố Hà Nội” [5] đã chỉ ra chỉ số an ninh nước của Hà Nội và chỉ số tổng hợp an ninh nước (WSI) tương ứng với các năm 2005, 2010 và 2015. Qua đó, nghiên cứu chỉ ra rằng các chỉ số an ninh nước của Thành phố Hà Nội tăng dần theo thời gian. Dựa trên phương pháp tính bình quân số học, coi trọng số của các chỉ số, nhóm chỉ số, khu vực, nghiên cứu đã chia Hà Nội thành 4 khu vực (Trung tâm, Bắc, Tây và Nam) và 5 nhóm chỉ số theo các tiêu chí: Hộ gia đình; Kinh tế; Mồi trường; Thiên tai và quản trị, quản lý.

Một trong những nghiên cứu gần đây về an ninh nước ở Việt Nam [6] nghiên cứu về an ninh nước cho phát triển bền vững lưu vực sông Mã. Nghiên cứu xây dựng được bộ chỉ số an ninh nước lưu vực sông Việt Nam gồm 18 chỉ số chia làm 6 nhón chỉ số an ninh nước: (i) Nhóm chỉ số an ninh nước liên quan đến nước đến lưu vực sông; (ii) Nhóm chỉ số an ninh nước liên quan đến cung cấp nước sạch cho dân sinh; (iii) Nhóm chỉ số an ninh nước dựa vào mức độ kinh tế sử dụng nước của lưu vực sông; (iv) Nhóm chỉ số an ninh nước liên quan đến bảo vệ hệ sinh thái và môi trường dòng sông; (v) Nhóm chỉ số an ninh nước dựa vào các rủi ro, thiệt hại do thiên tai; (vi) Nhóm chỉ số an ninh nước liên quan đến quản lý tài nguyên nước, quản lý lưu vực sông, phân cấp mức độ đảm bảo an ninh nước lưu vực. Trên cơ sở đó, nghiên cứu đã đề xuất một số định hướng giải pháp công trình, phi công trình nhằm đảm bảo an ninh nước lưu vực.

Trên thế giới, mặc dù có nhiều nghiên cứu về an ninh nước, kể cả các nghiên cứu đề xuất việc đánh giá, lượng hóa mức độ an ninh nước nhưng chưa có nhiều nghiên cứu đánh giá an ninh nước trong bối cảnh biến đổi khí hậu, đặc biệt là việc áp dụng các bộ chỉ số/bộ tiêu chí để đánh giá vấn đề này. Đối với tình hình trong nước, mặc dù đã có nhiều vấn đề phát sinh về an ninh nước trên cả nước nói chung và ở Quảng Ngãi nói riêng nhưng Việt Nam chưa có nhiều nghiên cứu về an ninh nước, ngay cả trong các văn bản pháp luật của Nhà nước cũng chưa đề cập đến vấn đề này, đặc biệt việc nghiên cứu an ninh nước trong điều kiện biến đồi khí hậu. Do đó Nghiên cứu nhằm đánh giá mức độ an ninh nước trong điều kiện biến đổi khí hậu tại Việt Nam thông qua bộ chỉ số, áp dụng thử nghiệm cho một tỉnh là Quảng Ngãi.

\section{Phương pháp và số liệu nghiên cứu}

\subsection{Phuơng pháp tính toán, lựa chọn chỉ số an ninh nước}

Phương pháp xin ý kiến chuyên gia là phương pháp được lựa chọn để xác định bộ chỉ số về an ninh nước. 
Quá trình lựa chọn các chỉ số an ninh nước được thực hiện cụ thể qua 8 bước, 3 giai đoạn trước, trong và sau khi tham vấn như sau:

- Giai đoạn trước khi tham vấn ý kiến chuyên gia:

+ Bước 1: Lựa chọn nhóm chuyên gia có liên quan tới quá trình tham vấn, số lượng 10 người (gồm các chuyên gia là những nhà khoa học, nhà quản lý liên quan đến nội dung nghiên cứu đến từ Viện Khoa học Khí tượng Thuỷ văn và Biến đổi khí hậu, Viện Khoa học tài nguyên nước, Trường Đại học Tài nguyên và Môi trường Hà Nội, Cục Quản lý tài nguyên nước, Cục Biến đổi khí hậu, Tổng cục Khí tượng Thuỷ văn, Sở Tài nguyên và Môi trường tỉnh Quảng Ngãi).

+ Bước 2: Xây dựng các chỉ số về an ninh nước dựa trên các tổng quan nghiên cứu và đánh giá sự phù hợp.

+ Bước 3 : Xây dựng các câu hỏi nhằm xin ý kiến tham vấn của các chuyên gia và các nhà khoa học liên quan.

- Giai đoạn tham vấn ý kiến chuyên gia:

+ Bước 4: Tiến hành tham vấn lần 1 . Buổi họp tham vấn ý kiến chuyên gia được tổ chức. Các chuyên gia được đề nghị đánh giá mức độ đồng thuận với bộ chỉ số đưa ra. Mức đồng thuận được sắp xếp từ 1-5 như sau: (i) rất không liên quan; (ii) không liên quan; (iii) có ít nhiều liên quan; (iv) liên quan; (v) rất liên quan.

+ Bước 5: Phân tích dữ liệu vòng 1 . Sau khi thu thập dữ liệu bằng Phương pháp Delphi, mỗi nhóm tác giả lựa chọn quy tắc khác nhau để tổng hợp và phân tích kết quả, hai quy tắc hay sử dụng là KAMET và Khung DPSIR (giá trị Kendal được để đánh giá sự phù hợp của chỉ số cần tham vấn. Mức độ đồng thuận được cho điểm theo các ngưỡng $0,0-0,1 ;>0,1-0,3$; $>0,3-0,5 ;>0,5-0,7 ;>0,7-1,0$ tương đương với mức độ đồng thuận rất yếu; yếu; trung bình; mạnh; rất mạnh).

Dựa vào kết quả đánh giá, các giá trị Trung vị $(\mathrm{Md})$; Độ lệch tứ phân vị $(\mathrm{Q})$; Giá trị trung bình (qi) và Phương sai (\%) theo quy tắc KAMET được tính toán.

+ Bước 6: Áp dụng phương pháp xin ý kiến chuyên gia vòng 2. Bảng câu hỏi được gửi cho các chuyên gia trong vòng 2 để tham vấn ý kiến đồng thuận hoặc mức độ ổn định trong câu trả lời của các thành viên. Chỉ số không được sử dụng khi một chuyên gia không trả lời chắc chắn các câu hỏi đưa ra [7].

- Giai đoạn sau khi tham vấn ý kiến chuyên gia:

+ Bước 7: Phân tích dữ liệu vòng 2. Sau khi dữ liệu được thu thập tại vòng 2, tiến hành phân tích kết quả. Việc phân tích dựa trên quy tắc KAMET như trên. Các chỉ số Trung vị $(\mathrm{Md})$; Độ lệch tứ phân vị $(\mathrm{Q})$; Giá trị trung bình (qi) và Phương sai (\%) được tính toán lại ở bước này.

Trong trường hợp tất cả các câu hỏi được chấp thuận hoặc từ chối; hoặc Giá trị trung bình cao hơn 3,5 và Phương sai thấp hơn $15 \%$, phương pháp xin ý kiến kết thúc [7].

+ Bước 8: Phân tích và tổng hợp kết quả. Căn cứ kết quả của các bước nêu trên, chỉ số cuối cùng được lựa chọn để thực hiện tính toán.

\subsection{Số liệu sử dụng trong tính toán}

Kịch bản biến đổi khí hậu tỉnh Quảng Ngãi được chiết xuất từ kịch bản biến đổi khí hậu và nước biển dâng cho Việt Nam cập nhật năm 2016 do Viện Khoa học Khí tượng Thủy văn và Biến đổi khí hậu [8] xây dựng như sau:

- Số liệu khí hậu thực đo đến 2014 được dùng cho việc hiệu chỉnh mô hình và so sánh kết quả tính toán với số liệu thực đo; số liệu này từ các trạm: An Chỉ, Ba Tơ, Lý Sơn, Quảng Ngãi, Sơn Giang.

- Kịch bản biến đổi khí hậu được xây dựng theo hai kịch bản nồng độ khí nhà kính là kịch bản trung bình RCP4.5 và kịch bản cao RCP8.5.

- Sự thay đổi trong tương lai của các biến khí hậu và mực nước biển là so với giá trị thực đo của thời kỳ cơ sở (1986-2005). 
- Kết quả tính toán từ các mô hình của các biến khí hậu được chiết xuất theo giá trị trung bình ngày trong giai đoạn từ năm 1986 đến năm 2100 .

- Biến đổi khí hậu trong tương lai được phân tích và trình bày cho giai đoạn đầu thế kỷ (2016-2035), giữa thế kỷ 21 (2046-2065) và cuối thế kỷ 21 (2080-2099).

- Các số liệu tự nhiên, kinh tế, xã hội được phân tích từ các kết quả điều tra, khảo sát, các tài liệu thu thập liên quan.

\section{Kết quả và thảo luận}

\subsection{Bộ chỉ số an ninh nước}

Bộ chỉ số cuối cùng sau khi xin ý kiến chuyên gia gồm 04 chỉ số chính và 17 chỉ số thành phần. Các chỉ số này đã bám sát định nghĩa của UN-Water như nêu tại phần mở đầu. Cụ thể, các chỉ số được mô tả và diễn giải theo các công thức tính toán như Bảng 1 .

Bảng 1. Chỉ số an ninh nước cả năm ở thời điểm hiện tại.

\begin{tabular}{cl}
\hline Chỉ số chính & \multicolumn{1}{c}{ Chỉ số cuối cùng sau khi xin ý kiến chuyên gia } \\
\hline Hệ sinh thái & Hiện trạng ô nhiễm \\
& Sức ép nước \\
& Chỉ số tài nguyên nước \\
& Mặt đệm \\
& Hệ số suy giảm hệ sinh thái \\
& Tần suất lũ \\
& Tần suất lũ \\
Thiên tai và hiểm họa & Số ngày hạn hán \\
liên quan đến nước & Tỉ lệ diện tích ngập lụt \\
& Lượng mưa trung bình năm \\
& Nhiệt độ trung bình năm \\
& Chi phí cho nước, vệ sinh \\
Kinh tế-Xã hội & Chi trả cho dịch vụ nước và nước thải \\
& Hệ số khan hiếm nước \\
Tài nguyên nước và số biến đổi nước đến lưu vực sông \\
con người & Hệ số khai thác nước \\
& Dân số được tiếp cận nước sạch \\
& Tỷ lệ người dân được tiếp cận hệ thống thu gom nước thải đạt tiêu chuẩn \\
\hline
\end{tabular}

\subsection{Tính toán an ninh nước của Quảng Ngãi ở thời điểm hiện tại}

\subsubsection{Chỉ số an ninh nước cả năm}

Chỉ số an ninh nước cả năm tính cho thời điểm hiện tại của cả tỉnh Quảng Ngãi được đánh giá ở mức cao $(0,61)$ (Bảng 2). Trong đó, chỉ số kinh tế-xã hội ở mức rất thấp $(0,1198)$, tiếp theo là chỉ số Tài nguyên nước và con người ở mức cao $(0,71)$, chỉ số Hệ sinh thái ở mức cao $(0,74)$, chỉ số Thiên tai và hiểm họa liên quan đến nước ở mức rất cao $(0,86)$. So sánh giữa các huyện về chỉ số an ninh nước cả năm ở thời điểm hiện tại, 08 huyện (Trà Bồng, Sơn Hà, Nghĩa Hành, Minh Long, Ba Tơ, Lý Sơn, Tây Trà, Sơn Tịnh) và thành phố Quảng Ngãi có chỉ số an ninh nước ở mức cao, dao động từ 0,61 đến 0,66 , trong đó huyện Sơn Hà là cao nhất ở mức 0,66 do có các chỉ số thành phần đều ở mức cao. Các huyện còn lại có chỉ số an ninh nước trung bình, dao động từ 0,46 (huyện Tư Nghĩa) đến 0,60 (huyện Mộ Đức) (Hình 1). 
Bảng 2. Chỉ số an ninh nước cả năm ở thời điểm hiện tại.

\begin{tabular}{|c|c|c|c|c|c|c|}
\hline TT & Huyện & $\begin{array}{l}\text { Hệ sinh } \\
\text { thái }\end{array}$ & $\begin{array}{c}\text { Thiên tai và } \\
\text { hiểm họa liên } \\
\text { quan đến nước }\end{array}$ & $\begin{array}{c}\text { Kinh } \\
\text { tế-xã hội }\end{array}$ & $\begin{array}{c}\text { Tài nguyên nước } \\
\text { và con người }\end{array}$ & $\begin{array}{c}\text { Chỉ số an ninh } \\
\text { nước cả năm }\end{array}$ \\
\hline 1 & Ba Tơ & 0,81 & 0,92 & 0,1304 & 0,74 & 0,65 \\
\hline 2 & Bình Sơn & 0,66 & 0,91 & 0,0586 & 0,75 & 0,60 \\
\hline 3 & Đức Phổ & 0,65 & 0,77 & 0,1488 & 0,75 & 0,58 \\
\hline 4 & Lý Sơn & 0,45 & 0,86 & 0,1222 & 0,41 & 0,46 \\
\hline 5 & $\begin{array}{l}\text { Minh } \\
\text { Long }\end{array}$ & 0,78 & 0,91 & 0,1241 & 0,73 & 0,64 \\
\hline 6 & Mộ Đức & 0,68 & 0,74 & 0,1709 & 0,75 & 0,59 \\
\hline 7 & $\begin{array}{l}\text { Nghĩa } \\
\text { Hành }\end{array}$ & 0,83 & 0,84 & 0,1760 & 0,76 & 0,65 \\
\hline 8 & Sơn Hà & 0,90 & 0,92 & 0,1122 & 0,71 & 0,66 \\
\hline 9 & Sơn Tây & 0,83 & 0,92 & 0,0503 & 0,68 & 0,62 \\
\hline 10 & Sơn Tịnh & 0,78 & 0,82 & 0,1179 & 0,75 & 0,61 \\
\hline 11 & Tây Trà & 0,76 & 0,92 & 0,1073 & 0,65 & 0,61 \\
\hline 12 & $\begin{array}{l}\text { TP Quảng } \\
\text { Ngãi }\end{array}$ & 0,68 & 0,86 & 0,0657 & 0,76 & 0,59 \\
\hline 13 & Trà Bồng & 0,79 & 0,92 & 0,1363 & 0,72 & 0,64 \\
\hline 14 & Tư Nghĩa & 0,75 & 0,79 & 0,1569 & 0,75 & 0,61 \\
\hline & Cả tỉnh & 0,74 & 0,86 & 0,1198 & 0,71 & 0,61 \\
\hline
\end{tabular}

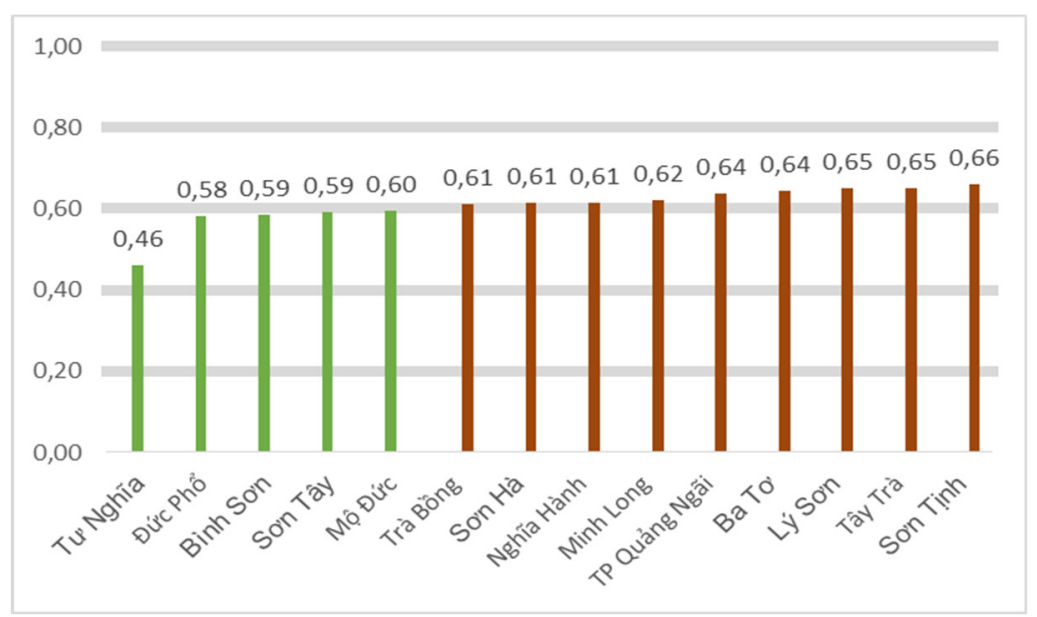

Hình 1. Chỉ số an ninh nước cả năm so sánh giữa các huyện ở thời điểm hiện tại.

\subsubsection{Chỉ số an ninh nước mùa cạn}

Chỉ số an ninh nước mùa cạn tính cho thời điểm hiện tại của cả tỉnh Quảng Ngãi được đánh giá ở mức trung bình $(0,59)$. Trong đó, chỉ số kinh tế-xã hội ở mức rất thấp $(0,1198)$, cả ba chỉ số Hệ sinh thái, Thiên tai và hiểm họa liên quan đến nước, Tài nguyên nước và con người đều ở mức cao (lần lượt là $0,73,0,80,0,69$ ) (Bảng 3).

Bảng 3. Chỉ số an ninh nước mùa cạn ở thời điểm hiện tại.

\begin{tabular}{llccccc}
\hline TT & Huyện & $\begin{array}{c}\text { Hệ sinh } \\
\text { thái }\end{array}$ & $\begin{array}{c}\text { Thiên tai và hiểm họa } \\
\text { liên quan đến nước }\end{array}$ & $\begin{array}{c}\text { Kinh } \\
\text { tế-xã hội }\end{array}$ & $\begin{array}{c}\text { Tài nguyên } \\
\text { nước và } \\
\text { con người }\end{array}$ & $\begin{array}{c}\text { Chỉ số an } \\
\text { ninh nước } \\
\text { cả năm }\end{array}$ \\
\hline 1 & Ba Tơ & 0,81 & 0,92 & 0,1304 & 0,74 & 0,65 \\
2 & Bình Sơn & 0,66 & 0,91 & 0,0586 & 0,75 & 0,60 \\
3 & Đức Phổ & 0,65 & 0,77 & 0,1488 & 0,75 & 0,58 \\
\hline
\end{tabular}




\begin{tabular}{|c|c|c|c|c|c|c|}
\hline TT & Huyện & $\begin{array}{l}\text { Hệ sinh } \\
\text { thái }\end{array}$ & $\begin{array}{l}\text { Thiên tai và hiểm họa } \\
\text { liên quan đến nước }\end{array}$ & $\begin{array}{c}\text { Kinh } \\
\text { tế-xã hội }\end{array}$ & $\begin{array}{c}\text { Tài nguyên } \\
\text { nước và } \\
\text { con người }\end{array}$ & $\begin{array}{l}\text { Chỉ số an } \\
\text { ninh nước } \\
\text { cả năm }\end{array}$ \\
\hline 4 & Lý Sơn & 0,45 & 0,86 & 0,1222 & 0,41 & 0,46 \\
\hline 5 & Minh Long & 0,78 & 0,91 & 0,1241 & 0,73 & 0,64 \\
\hline 6 & Mộ Đức & 0,68 & 0,74 & 0,1709 & 0,75 & 0,59 \\
\hline 7 & Nghĩa Hành & 0,83 & 0,84 & 0,1760 & 0,76 & 0,65 \\
\hline 8 & Sơn Hà & 0,90 & 0,92 & 0,1122 & 0,71 & 0,66 \\
\hline 9 & Sơn Tây & 0,83 & 0,92 & 0,0503 & 0,68 & 0,62 \\
\hline 10 & Sơn Tịnh & 0,78 & 0,82 & 0,1179 & 0,75 & 0,61 \\
\hline 11 & Tây Trà & 0,76 & 0,92 & 0,1073 & 0,65 & 0,61 \\
\hline 12 & $\begin{array}{l}\text { TP Quảng } \\
\text { Ngãi }\end{array}$ & 0,68 & 0,86 & 0,0657 & 0,76 & 0,59 \\
\hline 13 & Trà Bồng & 0,79 & 0,92 & 0,1363 & 0,72 & 0,64 \\
\hline 14 & Tư Nghĩa & 0,75 & 0,79 & 0,1569 & 0,75 & 0,61 \\
\hline & Cả tỉnh & 0,73 & 0,80 & 0,1198 & 0,69 & 0,59 \\
\hline
\end{tabular}

Về so sánh giữa chỉ số an ninh nước mùa cạn với chỉ số an ninh nước cả năm: hầu hết các huyện đều có chỉ số an ninh nước mùa cạn thấp hơn so với an ninh nước cả năm; trong đó chênh lệnh nhiều nhất là huyện Đức Phổ (mức chênh 0,06 ), các huyện còn lại và thành phố Quảng Ngãi có mức chênh giao động từ 0,01 đến 0,03 ; riêng huyện Lý Sơn thì ngược lại, chỉ số an ninh nước mùa cạn cao hơn cả năm với mức chênh 0,01 . Tính trên toàn tỉnh, chỉ số an ninh nước mùa cạn thấp hơn chỉ số an ninh nước cả năm là 0,02 (so sánh giữa 0,59 - mức an ninh nước trung bình và 0,61 - mức an ninh nước cao) (Hình 2).

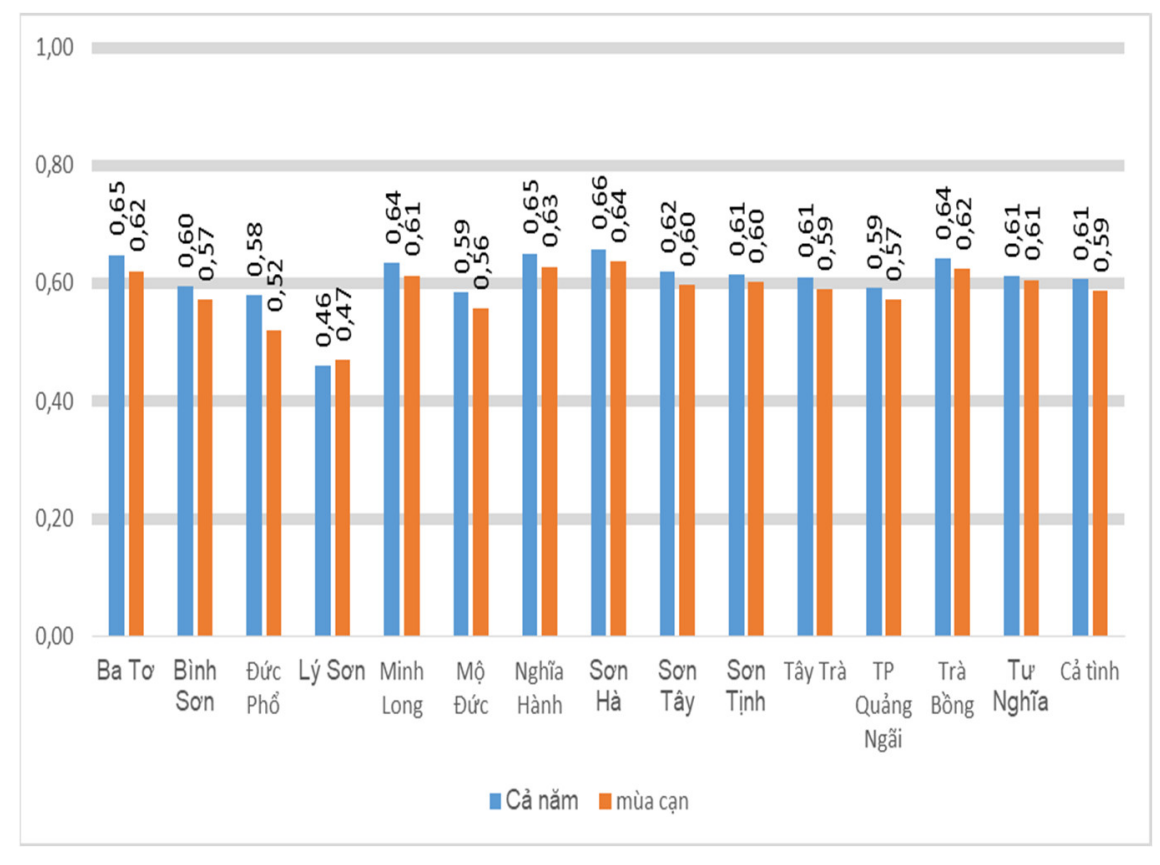

Hình 2. So sánh giữa chỉ số an ninh nước mùa cạn với chỉ số an ninh nước cả năm.

\subsubsection{Chỉ số an ninh nước mùa lũ}

Chỉ số an ninh nước mùa lũ tính cho thời điểm hiện tại của cả tỉnh Quảng Ngãi được đánh giá ở mức trung bình $(0,56)$. Trong đó, chỉ số kinh tế-xã hội ở mức rất thấp $(0,1198)$, ba chỉ số Hệ sinh thái, Tài nguyên nước và con người và chỉ số Thiên tai và hiểm họa liên quan đến nước ở mức cao (lần lượt là $0,70,0,71,0,71$ ) (Bảng 4). 
Bảng 4. Chỉ số an ninh nước mùa lũ ở thời điểm hiện tại.

\begin{tabular}{llccccc}
\hline TT & Huyện & $\begin{array}{c}\text { Hệ sinh } \\
\text { thái }\end{array}$ & $\begin{array}{c}\text { Thiên tai và hiểm họa } \\
\text { liên quan đến nước }\end{array}$ & $\begin{array}{c}\text { Kinh tế-xã } \\
\text { hội }\end{array}$ & $\begin{array}{c}\text { Tài nguyên nước } \\
\text { và con người }\end{array}$ & $\begin{array}{c}\text { Chỉ số an ninh } \\
\text { nước cả năm }\end{array}$ \\
\hline 1 & Ba Tơ & 0,87 & 0,74 & 0,1304 & 0,74 & 0,62 \\
2 & Bình Sơn & 0,68 & 0,73 & 0,0586 & 0,76 & 0,56 \\
3 & Đức Phổ & 0,74 & 0,70 & 0,1488 & 0,76 & 0,59 \\
4 & Lý Sơn & 0,62 & 0,67 & 0,1222 & 0,41 & 0,45 \\
5 & Minh Long & 0,88 & 0,72 & 0,1241 & 0,73 & 0,62 \\
6 & Mộ Đức & 0,62 & 0,66 & 0,1709 & 0,76 & 0,55 \\
7 & Nghĩa Hành & 0,63 & 0,70 & 0,1760 & 0,76 & 0,57 \\
8 & Sơn Hà & 0,70 & 0,76 & 0,1122 & 0,71 & 0,57 \\
9 & Sơn Tây & 0,80 & 0,74 & 0,0503 & 0,68 & 0,57 \\
10 & Sơn Tịnh & 0,58 & 0,69 & 0,1179 & 0,75 & 0,54 \\
11 & Tây Trà & 0,79 & 0,75 & 0,1073 & 0,65 & 0,57 \\
12 & TP. Quảng Ngãi & 0,48 & 0,74 & 0,0657 & 0,76 & 0,51 \\
13 & Trà Bồng & 0,88 & 0,74 & 0,1363 & 0,72 & 0,62 \\
14 & Tư Nghĩa & 0,56 & 0,65 & 0,1569 & 0,76 & 0,53 \\
& Cả tỉnh & $\mathbf{0 , 7 0}$ & $\mathbf{0 , 7 1}$ & $\mathbf{0 , 1 1 9 8}$ & $\mathbf{0 , 7 1}$ & $\mathbf{0 , 5 6}$ \\
\hline
\end{tabular}

Về so sánh giữa chỉ số an ninh nước mùa lũ với chỉ số an ninh nước cả năm: hầu hết các huyện đều có chỉ số an ninh nước mùa lũ thấp hơn so với an ninh nước cả năm; trong đó chênh lệnh nhiều nhất là 02 huyện Nghĩa Hành và Sơn Hà (đều có mức chênh 0,09 ), tiếp theo là 02 huyện Sơn Tịnh, Tư Nghĩa và thành phố Quảng Ngãi (đều có mức chênh 0,08 ); riêng huyện Đức Phổ thì ngược lại, chỉ số an ninh nước mùa lũ cao hơn cả năm với mức chênh 0,01 . Tính trên toàn tỉnh, chỉ số an ninh nước mùa lũ thấp hơn chỉ số an ninh nước cả năm là 0,05 (so sánh giữa 0,56 - mức an ninh nước trung bình và 0,61 - mức an ninh nước cao) (Hình $3)$.

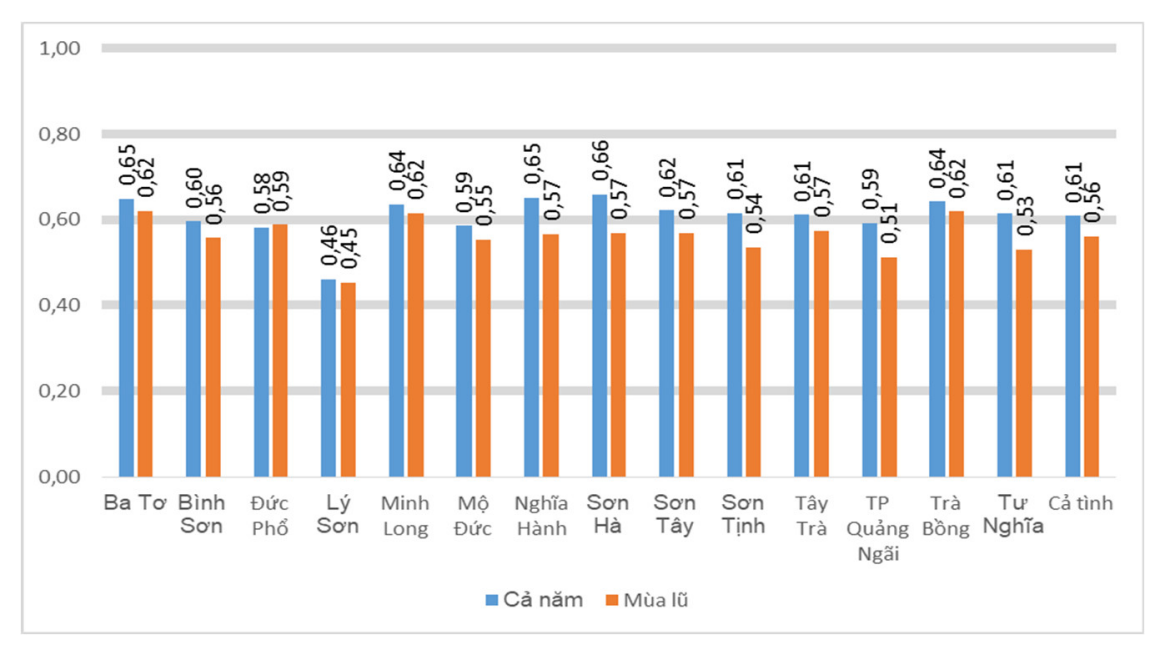

Hình 3. So sánh giữa chỉ số an ninh nước mùa lũ với chỉ số an ninh nước cả năm.

3.3. Tính toán an ninh cho thời kỳ turong lai (ở giai đoạn 2046 - 2065) có xét đến và không xét đến biến đổi khí hậu

3.3.1. Kết quả tính toán an ninh nước cho thời kỳ tương lai không xét đến biến đổi khí hậu

Chỉ số an ninh nước cả năm của tỉnh ở mức trung bình $(0,6)$. Trong đó: chỉ số kinh tế-xã hội ở mức rất thấp $(0,1189)$; các chỉ số Hệ sinh thái và chỉ số Tài nguyên nước và con người 
ở mức cao (lần lượt là 0,72 và 0,71$)$; chỉ số Thiên tai và hiểm họa liên quan đến nước ở mức rất cao $(0,86)$ (Bảng 5).

Bảng 5. Chỉ số an ninh nước trong tương lai không xét đến biến đổi khí hậu.

\begin{tabular}{llccccc}
\hline TT & \multicolumn{1}{c}{ Huyện } & $\begin{array}{c}\text { Hệ sinh } \\
\text { thái }\end{array}$ & $\begin{array}{c}\text { Thiên tai và hiểm } \\
\text { họa liên quan đến } \\
\text { nước }\end{array}$ & $\begin{array}{c}\text { Kinh tế } \\
- \text { Xã hội }\end{array}$ & $\begin{array}{c}\text { Tài nguyên } \\
\text { nước và con } \\
\text { người }\end{array}$ & $\begin{array}{c}\text { Chỉ số an } \\
\text { ninh nước } \\
\text { cả năm }\end{array}$ \\
\hline 1 & Ba Tơ & 0,77 & 0,92 & 0,1277 & 0,74 & 0,64 \\
2 & Bình Sơn & 0,64 & 0,91 & 0,0582 & 0,75 & 0,59 \\
3 & Đức Phổ & 0,63 & 0,77 & 0,1488 & 0,75 & 0,58 \\
4 & Lý Sơn & 0,44 & 0,86 & 0,1195 & 0,41 & 0,46 \\
5 & Minh Long & 0,75 & 0,91 & 0,1208 & 0,73 & 0,63 \\
6 & Mộ Đức & 0,67 & 0,74 & 0,1713 & 0,75 & 0,58 \\
7 & Nghĩa Hành & 0,81 & 0,84 & 0,1756 & 0,76 & 0,65 \\
8 & Sơn Hà & 0,87 & 0,92 & 0,1121 & 0,71 & 0,65 \\
9 & Sơn Tây & 0,80 & 0,92 & 0,0493 & 0,68 & 0,61 \\
10 & Sơn Tịnh & 0,76 & 0,82 & 0,1173 & 0,75 & 0,61 \\
11 & Tây Trà & 0,74 & 0,92 & 0,1048 & 0,65 & 0,60 \\
12 & TP Quảng Ngãi & 0,67 & 0,86 & 0,0650 & 0,76 & 0,59 \\
13 & Trà Bồng & 0,76 & 0,92 & 0,1379 & 0,72 & 0,63 \\
14 & Tư Nghĩa & 0,74 & 0,79 & 0,1561 & 0,75 & 0,61 \\
& Cả tỉnh & $\mathbf{0 , 7 2}$ & $\mathbf{0 , 8 6}$ & $\mathbf{0 , 1 1 8 9}$ & $\mathbf{0 , 7 1}$ & $\mathbf{0 , 6 0}$ \\
\hline
\end{tabular}

So sánh chỉ số an ninh nước giữa thời kỳ hiện tại với thời kỳ 2046-2065 chưa xét đến biến đổi khí hậu: về tổng thể chỉ số an ninh nước hầu như không biến động nhiều giữa hai thời kỳ này, xu hướng chung là an ninh nước ở thời kỳ 2046-2065 có thấp hơn nhưng không đáng kể. Cụ thể: có 09 huyện (Ba Tơ, Đức Phổ, Lý Sơn, Minh Long, Nghĩa Hành, Sơn Hà, Sơn Tây, Tây Trà và Trà Bồng) có mức an ninh nước ở thời kỳ thời kỳ 2046-2065 thấp hơn so với hiện tại (mức chênh tối thiểu 0,01); còn 04 huyện (Bình Sơn, Mộ Đức, Sơn Tịnh, Tư Ngĩa) và thành phố Quảng Ngãi có mức an ninh nước không thay đổi giữa hai thời kỳ. Xét cả tỉnh thì chỉ số an ninh nước ở thời kỳ tương lai chưa xét đến biến đổi khí hậu ở mức trung bình, trong khi đó ở thời kỳ hiện tại an ninh nước ở mức cao, nhưng mức chênh chỉ là tối thiếu $0,01(0,61$ so với 0,60$)$ (Hình 4).

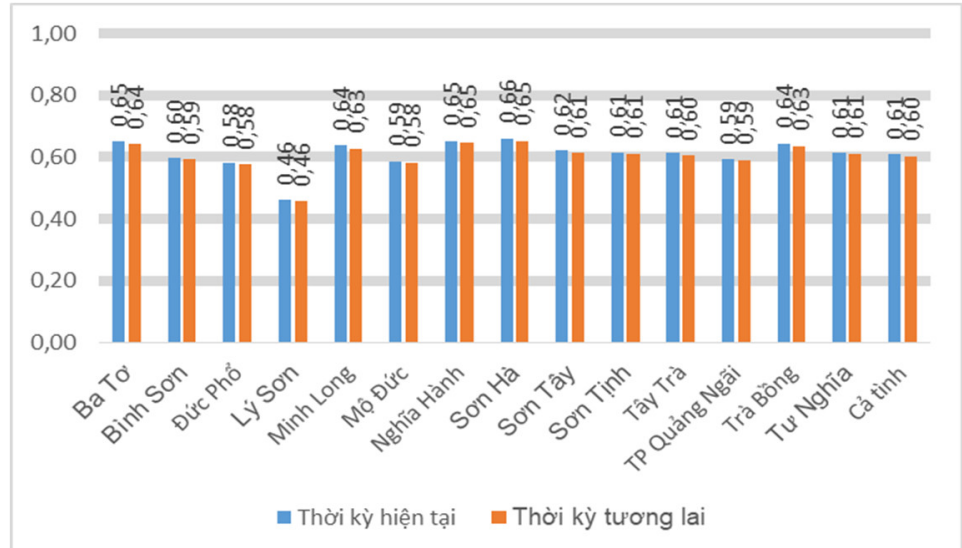

Hình 4. So sánh chỉ số an ninh nước giữa thời kỳ hiện tại với thời kỳ tương lai chưa xét đến biến đổi khí hậu.

3.3.2. Kết quả tính toán an ninh nước cho thời kỳ tương lai (giai đoạn 2046-2065) có xét đến biến đổi khí hậu (xét các kịch bản RCP4.5 và RCP8.5)

a) Kịch bản RCP 4.5 giai đoạn 2046-2065

Chỉ số an ninh nước cả năm theo kịch bản RCP4.5 thời kỳ 2046-2065 của cả tỉnh Quảng Ngãi được đánh giá ở mức trung bình $(0,58)$. Trong đó, chỉ số kinh tế-xã hội ở mức rất thấp 
$(0,1189)$, ba chỉ số còn lại là Hệ sinh thái, Thiên tai và hiểm họa liên quan đến nước, Tài nguyên nước và con người đều ở mức cao (lần lượt là $0,65,077$ và 0,79 ) (Bảng 6 ).

So sánh chỉ số an ninh nước giữa thời kỳ hiện tại với kịch bản RCP4.5 thời kỳ 2046-2065: chỉ số an ninh nước của 12 huyện và thành phố Quảng Ngãi ở thời kỳ hiện tại đều tốt hơn so với kịch bản RCP4.5 thời kỳ 2046-2065 (mức chênh từ 0,05 đến 0,01 ); chỉ riêng huyện Lý Sơn là ngược lại. Cụ thể: huyện Bình Sơn có mức chênh chỉ số an ninh nước nhiều nhất với 0,05 , ba huyện Nghĩa Hành, Sơn Hà, Sơn Tây có mức chênh 0,04 , ít nhất là thành phố Quảng Ngãi ở mức 0,01. Riêng huyện Lý Sơn chỉ số an ninh nước ở thời kỳ hiện tại kém hơn so với kịch bản RCP4.5 thời kỳ 2046-2065 với mức chênh 0,01 . Xét cả tỉnh thì chỉ số an ninh ở thời kỳ hiện tại cao hơn so với kịch bản RCP4.5 thời kỳ 2046-2065 với mức chênh 0,03 (so sánh giữa 0,61 - mức cao và 0,58 - mức trung bình) (Hình 5).

Bảng 6. Chỉ số an ninh nước cả năm theo kịch bản RCP4.5 thời kỳ 2046-2065.

\begin{tabular}{llccccc}
\hline TT & \multicolumn{1}{c}{ Huyện } & $\begin{array}{c}\text { Hệ sinh } \\
\text { thái }\end{array}$ & $\begin{array}{c}\text { Thiên tai và hiểm } \\
\text { họa liên quan đến } \\
\text { nước }\end{array}$ & $\begin{array}{c}\text { Kinh } \\
\text { tế-xã } \\
\text { hội }\end{array}$ & $\begin{array}{c}\text { Tài nguyên } \\
\text { nước và con } \\
\text { người }\end{array}$ & $\begin{array}{c}\text { Chỉ số an } \\
\text { ninh nước } \\
\text { cả năm }\end{array}$ \\
\hline 1 & Ba Tơ & 0,72 & 0,79 & 0,1277 & 0,84 & 0,62 \\
2 & Bình Sơn & 0,55 & 0,76 & 0,0582 & 0,81 & 0,54 \\
3 & Đức Phồ & 0,58 & 0,71 & 0,1488 & 0,82 & 0,56 \\
4 & Lý Sơn & 0,45 & 0,91 & 0,1195 & 0,41 & 0,47 \\
5 & Minh Long & 0,71 & 0,80 & 0,1208 & 0,81 & 0,61 \\
6 & Mộ Đức & 0,55 & 0,67 & 0,1713 & 0,84 & 0,56 \\
7 & Nghĩa Hành & 0,66 & 0,74 & 0,1756 & 0,87 & 0,61 \\
8 & Sơn Hà & 0,74 & 0,82 & 0,1121 & 0,79 & 0,62 \\
9 & Sơn Tây & 0,73 & 0,77 & 0,0493 & 0,76 & 0,58 \\
10 & Sơn Tịnh & 0,66 & 0,72 & 0,1173 & 0,82 & 0,58 \\
11 & Tây Trà & 0,66 & 0,84 & 0,1048 & 0,76 & 0,59 \\
12 & TP Quảng Ngãi & 0,67 & 0,75 & 0,0650 & 0,85 & 0,58 \\
13 & Trà Bồng & 0,73 & 0,80 & 0,1379 & 0,78 & 0,61 \\
14 & Tư Nghĩa & 0,68 & 0,69 & 0,1561 & 0,84 & 0,59 \\
& Cả tỉnh & $\mathbf{0 , 6 5}$ & $\mathbf{0 , 7 7}$ & $\mathbf{0 , 1 1 8 9}$ & $\mathbf{0 , 7 9}$ & $\mathbf{0 , 5 8}$ \\
\hline
\end{tabular}

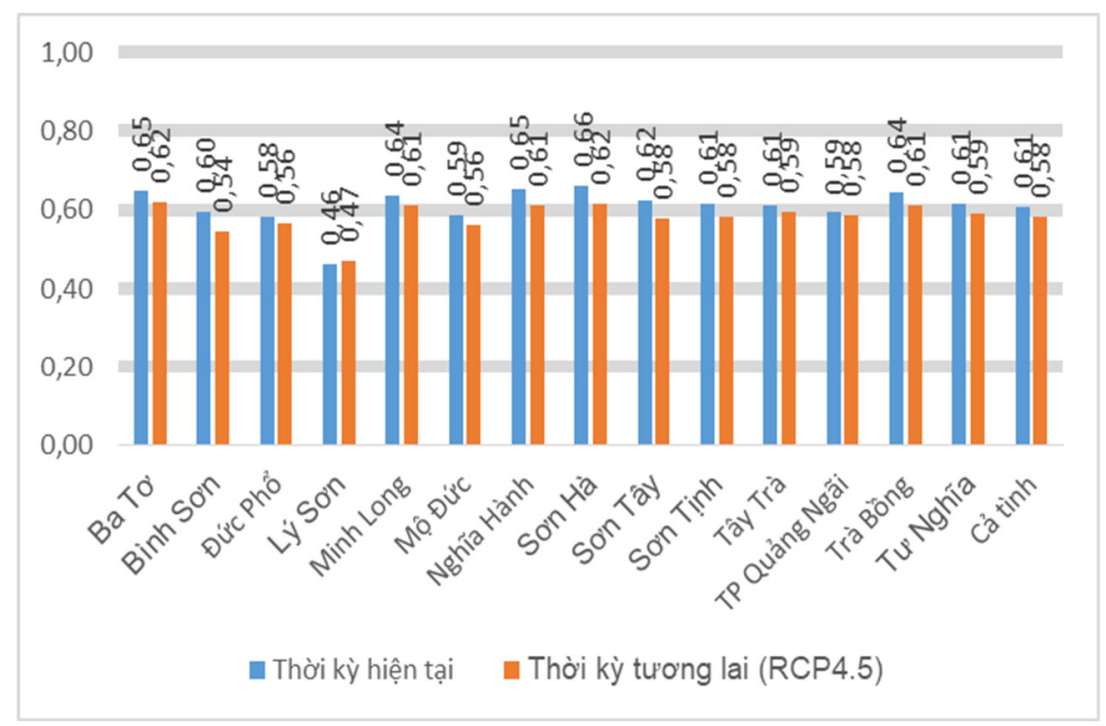

Hình 5. So sánh chỉ số an ninh nước giữa thời kỳ hiện tại với kịch bản RCP4.5 thời kỳ 2046-2065.

b) Kịch bản RCP 8.5 giai đoạn 2046-2065

Chỉ số an ninh nước cả năm theo kịch bản RCP8.5 thời kỳ 2046-2065 của cả tỉnh Quảng Ngãi được đánh giá ở mức trung bình $(0,57)$. Trong đó, chỉ số kinh tế-xã hội ở mức rất thấp 
$(0,1189)$, ba chỉ số còn lại là Hệ sinh thái, Thiên tai và hiểm họa liên quan đến nước, Tài nguyên nước và con người đều ở mức cao (lần lượt là $0,65,076$ và 0,77 ) (Bảng 7 ).

So sánh chỉ số an ninh nước giữa thời kỳ hiện tại với kịch bản RCP8.5 thời kỳ 2046-2065: chỉ số an ninh nước của 12 huyện và thành phố Quảng Ngãi ở thời kỳ hiện tại đều cao hơn so với kịch bản RCP8.5 thời kỳ 2046-2065 (mức chênh từ 0,06 đến 0,02 ); chỉ riêng huyện Lý Sơn là ngược lại. Cụ thể: huyện Bình Sơn có mức chênh chỉ số an ninh nước nhiều nhất với 0,06 , bốn huyện Nghĩa Hành, Sơn Hà, Sơn Tây, Sơn Tịnh có mức chênh 0,$05 ; 2$ huyện Đức Phổ, Tây Trà và thành phố Quảng Ngãi có mức chênh lệch ít nhất đều là 0,02 . Riêng huyện Lý Sơn chỉ số an ninh nước ở thời kỳ hiện tại kém hơn so với kịch bản RCP8.5 thời kỳ 2046-2065 với mức chênh 0,01. Xét cả tỉnh thì chỉ số an ninh ở thời kỳ hiện tại cao hơn so với kịch bản RCP8.5 thời kỳ 2046-2065 với mức chênh 0,04 (so sánh giữa 0,61 - mức cao và 0,57 - mức trung bình) (Hình 6).

Bảng 7. Chỉ số an ninh nước cả năm theo kịch bản RCP8.5 thời kỳ 2046-2065.

\begin{tabular}{llccccc}
\hline TT & \multicolumn{1}{c}{ Huyện } & $\begin{array}{c}\text { Hệ sinh } \\
\text { thái }\end{array}$ & $\begin{array}{c}\text { Thiên tai và hiểm } \\
\text { họa liên quan đến } \\
\text { nước }\end{array}$ & $\begin{array}{c}\text { Kinh } \\
\text { tế-xã } \\
\text { hội }\end{array}$ & $\begin{array}{c}\text { Tài nguyên } \\
\text { nước và con } \\
\text { người }\end{array}$ & $\begin{array}{c}\text { Chỉ số an } \\
\text { ninh nước } \\
\text { cả năm }\end{array}$ \\
\hline 1 & Ba Tơ & 0,72 & 0,78 & 0,1277 & 0,81 & 0,61 \\
2 & Bình Sơn & 0,55 & 0,75 & 0,0582 & 0,80 & 0,54 \\
3 & Đức Phố & 0,58 & 0,71 & 0,1488 & 0,80 & 0,56 \\
4 & Lý Sơn & 0,45 & 0,91 & 0,1195 & 0,41 & 0,47 \\
5 & Minh Long & 0,71 & 0,78 & 0,1208 & 0,80 & 0,60 \\
6 & Mộ Đức & 0,55 & 0,65 & 0,1713 & 0,82 & 0,55 \\
7 & Nghĩa Hành & 0,66 & 0,73 & 0,1756 & 0,84 & 0,60 \\
8 & Sơn Hà & 0,74 & 0,81 & 0,1121 & 0,78 & 0,61 \\
9 & Sơn Tây & 0,73 & 0,77 & 0,0493 & 0,75 & 0,57 \\
10 & Sơn Tịnh & 0,66 & 0,69 & 0,1173 & 0,81 & 0,57 \\
11 & Tây Trà & 0,66 & 0,84 & 0,1048 & 0,75 & 0,59 \\
12 & TP Quảng Ngãi & 0,67 & 0,72 & 0,0650 & 0,84 & 0,57 \\
13 & Trà Bồng & 0,73 & 0,81 & 0,1379 & 0,77 & 0,61 \\
14 & Tư Nghĩa & 0,67 & 0,65 & 0,1561 & 0,83 & 0,58 \\
& Cả tỉnh & $\mathbf{0 , 6 5}$ & $\mathbf{0 , 7 6}$ & $\mathbf{0 , 1 1 8 9}$ & $\mathbf{0 , 7 7}$ & $\mathbf{0 , 5 7}$ \\
\hline
\end{tabular}

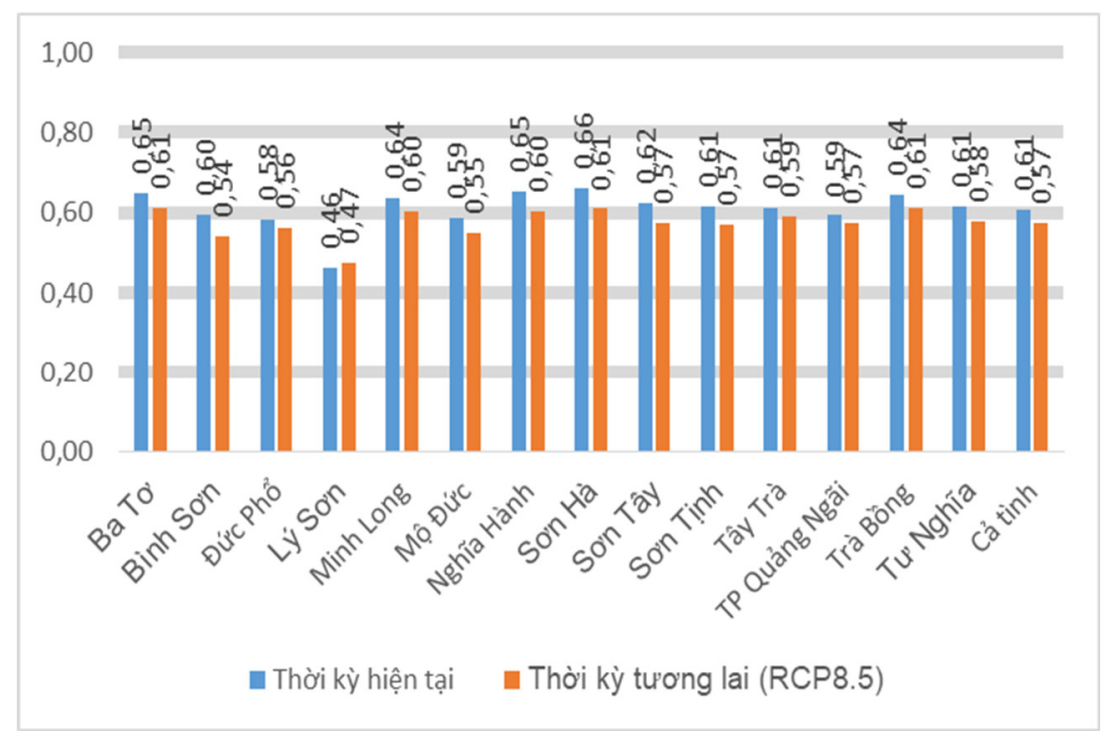

Hình 6. So sánh chỉ số an ninh nước giữa thời kỳ hiện tại với kịch bản RCP8.5 thời kỳ 2046-2065.

Hình dưới đây thể hiện sự khác nhau giữa an ninh nước ở thời kỳ hiện tại và thời kỳ tương lai có xét đến biến đổi khí hậu ở kịch bản RCP 4.5 và RCP 8.5. 


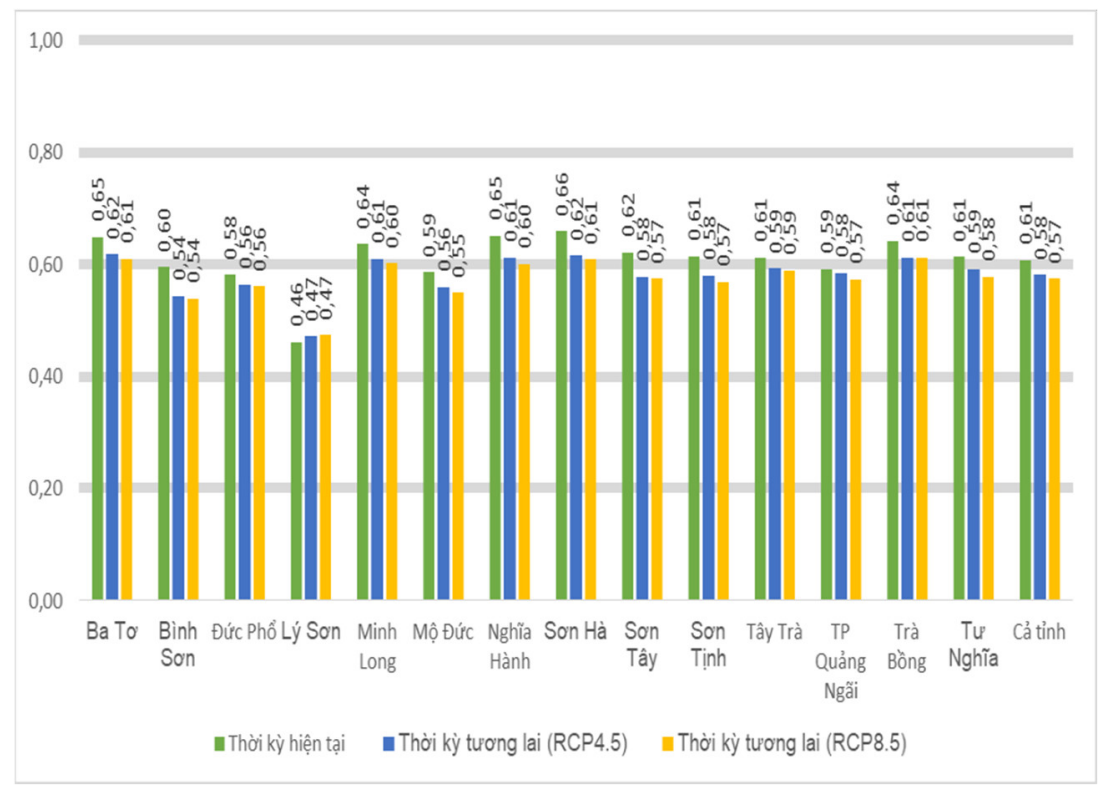

Hình 7. So sánh chỉ số an ninh nước giữa thời kỳ hiện tại và giai đoạn 2046-2065 ở cả hai kịch bản RCP4.5 và kịch bản RCP8.5.

\section{Kết luận}

Thông qua các kết quả áp dụng bộ chỉ số để tính toán tại tỉnh Quảng Ngãi, chỉ số an ninh nước của cả tỉnh ở các thời điểm và các kịch bản như sau:

- Ở thời điểm hiện tại, chỉ số an ninh nước cả năm tính cho thời điểm hiện tại của cả tỉnh Quảng Ngãi được đánh giá ở mức cao. 08 huyện (Trà Bồng, Sơn Hà, Nghĩa Hành, Minh Long, Ba Tơ, Lý Sơn, Tây Trà, Sơn Tịnh) và thành phố Quảng Ngãi có chỉ số an ninh nước ở mức cao, các huyện còn lại có chỉ số an ninh nước trung bình.

- Ở giai đoạn 2046-2065:

+ So sánh chỉ số an ninh nước giữa thời kỳ hiện tại với thời kỳ 2046-2065 chưa xét đến biến đổi khí hậu thì về tổng thể chỉ số an ninh nước hầu như không biến động nhiều giữa hai thời kỳ này, xu hướng chung là an ninh nước ở thời kỳ 2046-2065 có thấp hơn nhưng không không đáng kể. Chỉ số an ninh nước cả năm của tỉnh Quảng Ngãi được đánh giá ở mức cao.

+ Trong khi đó, với kịch bản RCP4.5 thời kỳ 2046-2065 (tức là có xét đến biến đổi khí hậu) thì chỉ số an ninh nước cả tỉnh chỉ ở mức trung bình, thấp hơn so với thời điểm hiện tại (so sánh giữa 0,61 ở thời điểm hiện tại - mức cao với 0,58 ở thời kỳ 2046-2065 kịch bản RCP4.5 - mức trung bình).

+ Tiếp theo, nểu so sánh chỉ số an ninh nước giữa thời kỳ hiện tại với kịch bản RCP8.5 thời kỳ 2046-2065 (kịch bản cực đoan hơn) thì chỉ số an ninh nước cũng chênh lệch nhiều hơn so với kịch bản RCP4.5 với mức chênh 0,04 (so sánh giữa 0,61 ở thời điểm hiện tại - mức cao với 0,57 ở thời kỳ 2046-2065 kịch bản RCP4.5 - mức trung bình). đề sau:

Những hạn chế trong phạm vi về thời gian và nội dung, bài báo chưa đề cập đến các vấn

- Chưa xây dựng được trọng số của các chỉ số cũng như nhóm chỉ số đánh giá an ninh nước, điều này dẫn đến việc chưa sắp xếp được thứ tự chỉ số thành phần nào tác động đến chỉ số an ninh nước cuối cùng nhiều hay ít.

- Chỉ số thành phần đầu vào liên quan đến nhiều ngành, lĩnh vực, số liệu tính toán cho cả giai đoạn hơn 100 năm, phải chia ra các thời kỳ, nên một số chỉ số dùng mô hình để tính toán hoặc ngoại suy.

Đóng góp của tác giả: Xây dựng ý tưởng nghiên cứu: B.Đ.H., H.T.L.H.; Lựa chọn phương pháp nghiên cứu: H.T.L.H., Đ.Q.T.; Xử lý số liệu: N.T.L., N.V.Đ.; Viết bản thảo bài báo: B.Đ.H., H.T.L.H., Đ.Q.T., N.T.L., N.V.Đ., N.A.T.; Chỉnh sửa bài báo: N.V.Đ., N.A.T. 
Lời cảm ơn: Tập thể tác giả trân trọng cảm ơn sự giúp đỡ của các cơ quan trực thuộc Bộ Tài nguyên và Môi trường gồm: Viện Khoa học Khí tượng Thủy văn và Biến đổi khí hậu, Cục Quản lý tài nguyên nước, Cục Biến đổi khí hậu, Văn phòng Bộ; và Sở Tài nguyên và Môi trường tỉnh Quảng Ngãi trong quá trình khảo sát và thực hiện nghiên cứu này.

Lời cam đoan: Tập thể tác giả cam đoan bài báo này là công trình nghiên cứu của tập thể tác giả, chưa được công bố ở đâu, không được sao chép từ những nghiên cứu trước đây; không có sự tranh chấp lợi ích trong nhóm tác giả.

\title{
Tài liệu tham khảo
}

1. UN-Water. Water Security \& the Global Water Agenda A UN-Water Analytical Brief. 2014.

2. WaterAid. Water security framework. 2012.

3. GWP. Assessing water security with appropriate indicators, Proceedings from the GWP workshop. 2014.

4. Xiaoli, J.; Chunhui, L.; Yanpeng, C.; Xuan, W.; Lian, S. An improved method for integrated water security assessment in the Yellow River basin, China. 2015.

5. Hải, N.Đ. Phát triển và ứng dụng một khung đánh giá an ninh nguồn nước cho thành phố Hà Nội. 2015.

6. Mùi, N.T. Nghiên cứu an ninh nguồn nước cho phát triển bền vững lưu vực sông Mã. Luận án tiến sỹ Đại học Thủy lợi. 2019.

7. Chu, H.C.; Hwang, G.J. A Delphi-based approach to developing expert systems with the cooperation of multiple experts. 2007.

8. Viện Khoa học Khí tượng Thủy văn và Biến đổi khí hậu. Kịch bản biến đổi khí hậu và nước biển dâng cho Việt Nam. 2016.

\section{Water Security Assessment Results of Quang Ngai Province in the Context of Climate Change}

\author{
Bui Duc Hieu ${ }^{*}$, Huynh Thi Lan Huong², Dang Quang Thinh ${ }^{2}$, Nguyen Van Dai ${ }^{2}$, \\ Nguyen Thi Lieu², Nguyen Anh Tuan² \\ 1 Ministerial Office, Ministry of Natural Resources and Environment; \\ duchieucect@gmail.com; \\ ${ }^{2}$ Member of 15 National Assembly, Vietnam Administration of Seas and Islands, Ministry \\ of Natural Resources and Environment; tadinhthi@gmail.com; \\ 3 Vietnam Institute of Meteorology, Hydrology and Climate Change, Ministry of Natural \\ Resources and Environment; huynhlanhuong@gmail.com; thinhdangq@gmail.com; \\ nguyendai.tv@gmail.com; lieuminh2011@gmail.com; athnvn@gmail.com;
}

\begin{abstract}
There are many researches on water security, including water securrity assessments and quantifications, but there is few studies on applying indicators to assess water security in the context of climate change. In this paper, a set of indicators were developed to assess water security based on climate change projections of Quang Ngai province. Indicator-based assessment results were calculated based on investigation data and were thresholded from very low to very high. The results show that: (i) future water security indices are lower than present; (ii) climate change related water security indices are lower than non-climate change indices; (iii) water security indices in RCP8.5 are lower than in RCP4.5 in the period of 2046-2065. These results are key information to propose measures for enhancing water security situations in Quang Ngai province.
\end{abstract}

Keywords: Water Security; Climate Change; Quang Ngai. 